Journal of Patient-Centered

\title{
Mindfulness-Based Stress Reduction and Transcendental Meditation: Current State of Research
}

Adam Holt

Follow this and additional works at: https://aah.org/jpcrr

Part of the Alternative and Complementary Medicine Commons, Medical Physiology Commons, Movement and Mind-Body Therapies Commons, Other Mental and Social Health Commons, and the Primary Care Commons

\section{Recommended Citation}

Holt A. Mindfulness-based stress reduction and transcendental meditation: current state of research. J Patient Cent Res Rev. 2015;2:64-68. doi: 10.17294/2330-0698.1199

Published quarterly by Midwest-based health system Advocate Aurora Health and indexed in PubMed Central, the Journal of Patient-Centered Research and Reviews (JPCRR) is an open access, peer-reviewed medical journal focused on disseminating scholarly works devoted to improving patient-centered care practices, health outcomes, and the patient experience. 


\title{
Mindfulness-Based Stress Reduction and Transcendental Meditation: Current State of Research
}

\author{
Adam Holt, MD \\ Family Medicine Residency Program, Aurora Health Care, Milwaukee, WI
}

\begin{abstract}
This article summarizes the current state of meditation research, specifically focusing on mindfulnessbased stress reduction and transcendental meditation. Despite significant methodological problems with the studies reported to date on the subject, there is consistent evidence that meditation can produce changes in the nervous system and physiology of the meditator, and can help with various psychological markers of well-being. Regarding improvement in specific clinical diseases, research is generally mixed and preliminary. Strong recommendations cannot be made based on current evidence, and further studies are needed. In general, there is a stronger body of evidence supporting mindfulness-based stress reduction than for transcendental meditation. (J Patient-Centered Res Rev. 2015;2:64-68.)
\end{abstract}

Keywords meditation, transcendental meditation, mindfulness-based stress reduction

The purpose of this paper is to summarize relevant portions of the research on two types of meditation practices. Meditation is a heterogeneous discipline. Different methods might fall into the category of "meditation," ranging from mindfulness-based stress reduction (MBSR) to tai chi to yoga to prayer. This article focuses on two relatively defined entities with significant research literature - MBSR and transcendental meditation (TM). Challenges in interpretation are numerous, but a significant body of research has nonetheless accumulated and is discussed herein. The goal is to provide an easily accessible resource for physicians and other health care professionals to use when recommending these types of meditation to patients.

MBSR is a behavioral medicine program created by Jon Kabat-Zinn in the late 1970s. ${ }^{1}$ It uses the foundation of "mindfulness" to help people better deal with their lives. It is a secular method that requires training/certification to lead, and has standardized methods. It involves mindfulness meditation training, body scanning and simple yoga postures. Largely due to its secular nature,

Correspondence: Adam Holt, MD, 4600 W. Loomis Road, Suite \#130, Greenfield, WI, 53220, T: 414-649-6732,

F: 414-649-3361, Email: adamholt84@gmail.com
MBSR has been studied at some length. Likewise, TM is a simple method of meditation involving focusing on a mantra. A mantra is a word or set of words that is repeated as an object of focus. It may or may not have a clear meaning - sometimes the sound itself is the object of focus rather than an intellectual meaning. ${ }^{2}$ It has roots in the Hindu tradition of India, but also could be considered a secular technique as it does not require a belief system. In general, it consists of meditating on a mantra for 15-20 minutes, twice per day, with eyes closed. It also is one of the more widely studied forms of meditation. Despite having a fairly large body of published research, it was decided that yoga would not be included in this analysis. It was felt this would be more confusing than helpful given the fundamental difference between a physical yoga technique and these more sedentary meditation techniques.

\section{METHODS}

PubMed searches with no restrictions regarding publication date were performed for the keywords meditation, mindfulness-based stress reduction, MBSR, mindfulness, transcendental meditation and immune response. There were no strict inclusion or exclusion criteria, the primary reason being that the purpose of this paper is a general overview, not a formal systematic analysis. The investigative methods used in the resulting articles vary greatly and do not lend themselves to strict selection criteria. To exemplify this 
point, the 2012 meta-analysis by Sedlmeier et al. ${ }^{3}$ used strict inclusion/exclusion criteria and omitted almost $75 \%$ of the papers available. We determined important information may be left out by the use of strict criteria while fully acknowledging the subjective aspects of this narrative review. In general, an effort was made to include well-constructed, specific studies with relevant findings. Numerous studies relating to highly specific interventions (such as one-on-one interventions with a particular person) and studies with undefined methods of meditation were excluded.

\section{RESULTS}

In total, 55 articles were examined and 36 were summarized in this review within the context of three subheadings: physiology, clinical psychology and clinical medical research.

\section{Physiology}

It appears clear changes occur in the central nervous systems of those who meditate, such as increases in grey matter concentration, decreased in brain activity in areas related to stressful states of mind, and neural rewiring. These changes were found in the frontal lobe, anterior cingulate gyrus, fusiform gyrus, occipital lobe, amygdala, hippocampus, thalamus and brainstem, ${ }^{4-8}$ and were found in healthy individuals, individuals with generalized anxiety disorder and patients with Parkinson's disease. In no cases were these changes associated with any negative outcomes, and the changes were sometimes correlated with positive psychological outcomes such as selfacceptance, purpose in life, autonomy and others. ${ }^{6}$ Eight of the studies examined primarily dealt with physiology, and all of these included significant changes between the control group and its respective study group.

Apart from the central nervous system, there is evidence for various other physiological changes with MBSR, including increased telomerase activity, which is a marker of cellular aging, psychological stress and disease risk. In patients with breast cancer, MBSR increases activity in peripheral mononuclear cells, suggesting potential beneficial effects of MBSR on cell longevity in this setting. ${ }^{8}$ In addition, use of MBSR has been associated with increased natural killer cell activity in patients with human immunodeficiency virus (although no significant clinical differences), ${ }^{9}$ lower inflammatory responses, ${ }^{9}$ increase in antibody titers to an influenza vaccine ${ }^{10}$ and improvements in immune system function after strenuous physical stress. ${ }^{11}$

\section{Clinical Psychology}

Regarding psychological effects of meditation, it appears MBSR can help prevent burnout in various fields, including nursing, teaching, medicine and family caregiving. ${ }^{12-15}$ A beneficial effect for patients with posttraumatic stress disorder (PTSD) was repeatedly shown with both TM and MBSR, including improvements in depression, fatigue and tension. ${ }^{16,17}$ Generally, MBSR was found to help with insomnia, though it was not superior to cognitive behavioral therapy. ${ }^{18-21}$ Regarding stress, anxiety and depression, MBSR has a significant research basis supporting benefit. ${ }^{22-27}$ A 2011 meta-analysis concluded that MBSR is a "useful method for improving mental health and reducing symptoms of stress, anxiety and depression." ${ }^{24}$ In regards to TM, there is some evidence it can be helpful for anxiety and depression, but it also has been noted that there are considerable flaws in many TM studies as well as a possibly strong selection bias toward people favorable to the practice..$^{28-30}$

\section{Clinical Medicine}

This is the weakest area of positive research findings on meditation. Regarding prehypertension or hypertension, a weak positive effect was found for MBSR but only in clinic readings. ${ }^{31}$ Regarding TM and hypertension, a 2004 review concluded there were many methodological problems with the research to date on TM's effect on hypertension, and the authors all had affiliations with TM, suggesting possible bias. ${ }^{32}$ Only a weak recommendation could be made for MBSR to treat fibromyalgia. ${ }^{33}$ MBSR was not found to affect the rate or severity of exacerbations in patients with ulcerative colitis. ${ }^{34}$ However, it can be noted that MBSR did increase quality of life in those patients despite not decreasing their exacerbations. Of note, many of the aforementioned physiological studies potentially suggest there may be clinical benefits from meditation in various medical diseases, such as cancer, immune system problems and inflammatory diseases, but there is not a strong body of evidence in support of actual clinical outcomes at this point.

In all of the studies analyzed for this paper, the author did not discover any reason to avoid the use 
of meditation. There were no major complications reported and no increase in mortality or morbidity.

\section{DISCUSSION}

In general, there are quite significant limitations to a review such as this, and each will be broken down in a systematic manner. However, it is worth noting that significant research has been reported, and it may be unwise to completely dismiss these findings based on analytical shortcomings.

First, regarding the challenge of analyzing meditation, there is a fundamental problem with defining the word or category. ${ }^{35}$ Much like there are many activities bowling, basketball, swimming, etc. - listed under the category "sports," there are many subcategories of meditation with different methods, goals and results. This makes the study of "meditation" as a whole quite difficult from a large-scale perspective. Therefore, this paper mostly focuses on two relatively well-defined types of meditation, MBSR and TM. MBSR is, at least in theory, well-defined in its implementation, and TM is relatively standardized in its practice. However, even within this structure, there are likely substantial differences between one practitioner or teacher and another.

Second, there were no defined inclusion or exclusion criteria because of the vast heterogeneity of the studies done on meditation to date. Most studies are relatively small, with low overall power, and methods vary greatly. ${ }^{36}$ The populations also vary greatly or are not specifically defined. Many or most of the studies would be considered pilot investigations, which might show some preliminary data and suggest a role for further research. If strict inclusion criteria were imposed, the majority of papers would be excluded for these reasons. Certainly it is worth noting that many of the articles included in this paper's reference list are from 2013 or 2014, and new articles are coming out rapidly. This seems to show there is significant interest from the research community in the topic, presumably based on the (often promising) preliminary research to date.

Given the absence of inclusion and exclusion criteria, there is also the possibility of personal bias on the part of the author. The author has practiced meditation for more than a decade and feels it is a worthwhile pursuit. It is possible this could have resulted in selection bias.
The author attempted to present a fair overview of the current evidence.

Third, as mentioned, due to the nature of the reported research, many of the conclusions simply do not have strong statistical power. There are occasions of conflicting results or weak study methods. Again, most studies to date are of a "preliminary" nature. An attempt was made to delineate such studies in the Results section, but the simple fact is that many of the studies had a small budget, a small population and, as such, small statistical power. As stated in many of the papers analyzed, more rigorous, large-scale studies would have to be performed in order to get strong statistics.

Finally, and the author believes this is a crucial point, the risk-benefit analysis of these techniques is important. As stated centuries ago, our first priority is primum no nocere, or do no harm. In all of the papers examined, no significant negative effects from the practice of meditation, whether TM or MBSR, were reported. Theoretically, one could argue that meditation could be harmful if used in place of other more established treatment without significant evidence for benefit, that is, if used as a primary treatment without sufficient evidence. However, as an adjunctive treatment, it appears to be safe and cost-effective, and the studies published to date suggest potential benefit in many cases. Of note, despite no clear contraindication for patients with psychotic features based on clinical studies, it appears reasonable to withhold recommending meditation to these patients until stronger evidence exists.

As a counterpoint, we can consider the need for evidence to support new pharmacological agents. Research supporting a new medication approval must be highly rigorous, as the pharmaceuticals we use can often have severe side effects. Historically, the potential for harm with a new (or even somewhat established) drug is moderate to high, whereas the potential for harm when a clinician recommends meditation appears to be minimal.

In general meditation, at best, is an efficient, essentially harmless, potentially beneficial adjunct to other medical treatment. Implementation is relatively low cost compared to other interventions, but this cost advantage is somewhat offset by lack of insurance coverage - MBSR training, for example, may cost a patient $\sim \$ 400.37-39$ More benefits may be uncovered by future research and experience. At worst, meditation costs a relatively small 
amount of money for training, takes up a relatively small amount of time and may provide no actual benefit.

Meditation is a difficult to define clinical entity, and rigorous broad-scale research has thus far encountered significant obstacles. However, research to date does suggest that it may have a role in patient care. Many small studies on meditation suggest there could be benefit in a wide range of clinical applications, from enhancement of immune response to improvements in psychological well-being to better clinical outcomes for certain medical problems. The strongest research demonstrates clear benefit in various psychological markers and various physiological changes, with weaker evidence for potential benefit in some clinical disease states. However, as a whole, the current state of the literature is preliminary and generally not statistically powerful. Large-scale research is needed to further define the clinical roles that meditation could effectively play. Specific to this paper, it appears there is currently a stronger body of evidence in support of MBSR than of TM, partly due to flaws in many studies related to the latter.

\section{CONCLUSIONS}

Despite a heterogeneous and mixed-quality body of evidence, given the risk-benefit ratio and current evidence, it is a reasonable clinical decision to suggest or recommend a meditation practice like mindfulnessbased stress reduction as an adjunctive treatment for selected clinical conditions such as anxiety, depression, insomnia, PTSD, burnout or cancer, and to promote general well-being. This assertion can be made largely because the potential for harm is extremely low, the cost includes only that of training, and preliminary studies suggest meditation may be of potential benefit in several clinical or behavioral situations.

\section{Patient-Friendly Recap}

- Structured meditation can provide physiological and psychological health benefits.

- Its role in clinical medicine for treating various stress-related health conditions remains inconclusive.

- No complications or harmful effects are noted in the literature for those who practice mindfulnessbased stress reduction or transcendental meditation.

\section{Acknowledgments}

The author gives special thanks to Dr. Dennis Baumgardner and three anonymous reviewers for offering helpful manuscript suggestions.

\section{Conflicts of Interest}

None.

\section{REFERENCES}

1. Mindful Living Programs. What is mindfulness-based stress reduction? http://www.mindfullivingprograms.com/ whatMBSR.php. Accessed May 7, 2014.

2. Maharishi Foundation. Transcendental meditation: inner peace and wellness. http://www.tm.org. Accessed May 7, 2014.

3. Sedlmeier P, Eberth J, Schwarz M, et al. The psychological effects of meditation: a meta-analysis. Psychol Bull. 2012;138:1139-71. CrossRef

4. Hölzel BK, Hoge EA, Greve DN, et al. Neural mechanisms of symptom improvements in generalized anxiety disorder following mindfulness training. Neuroimage Clin. 2013; 2:448-58. CrossRef

5. Pickut BA, Van Hecke W, Kerckhofs E, et al. Mindfulness based intervention in Parkinson's disease leads to structural brain changes on MRI: a randomized controlled longitudinal trial. Clin Neurol Neurosurg. 2013;115:2419-25. CrossRef

6. Singleton O, Hölzel BK, Vangel M, Brach N, Carmody J, Lazar SW. Change in brainstem gray matter concentration following a mindfulness-based intervention is correlated with improvement in psychological well-being. Front Hum Neurosci. 2014;8:33. $\underline{\text { CrossRef }}$

7. Davidson RJ, Kabat-Zinn J, Schumacher J, et al. Alterations in brain and immune function produced by mindfulness meditation. Psychosom Med. 2003;65:564-70. CrossRef

8. Lengacher CA, Reich RR, Kip KE, et al. Influence of mindfulness-based stress reduction (MBSR) on telomerase activity in women with breast cancer (BC). Biol Res Nurs. 2014;16:438-47. CrossRef

9. Rosenkranz MA, Davidson RJ, Maccoon DG, Sheridan JF, Kalin NH, Lutz A. A comparison of mindfulnessbased stress reduction and an active control in modulation of neurogenic inflammation. Brain Behav Immun. 2013; 27:174-84. CrossRef

10. Robinson FP, Mathews HL, Witek-Janusek L. Psychoendocrine-immune response to mindfulness-based stress reduction in individuals infected with the human immunodeficiency virus: a quasiexperimental study. J Altern Complement Med. 2003;9:683-94. CrossRef

11. Solberg EE, Halvorsen R, Sundgot-Borgen J, Ingjer F, Holen A. Meditation: a modulator of the immune response to physical stress? A brief report. Br J Sports Med. 1995; 29:255-7. CrossRef

12. Flook L, Goldberg SB, Pinger L, Bonus K, Davidson RJ. Mindfulness for teachers: a pilot study to assess effects on stress, burnout and teaching efficacy. Mind Brain Educ. 2013;7:182-95. CrossRef

13. Moody K, Kramer D, Santizo RO, et al. Helping the helpers: mindfulness training for burnout in pediatric oncology--a pilot program. J Pediatr Oncol Nurs. 2013;30:275-84. CrossRef 
14. Romani M, Ashkar K. Burnout among physicians. Libyan $J$ Med. 2014;9:23556. CrossRef

15. Hou RJ, Wong SY, Yip BH, et al. The effects of mindfulnessbased stress reduction program on the mental health of family caregivers: a randomized controlled trial. Psychother Psychosom. 2014;83:45-53. CrossRef

16. Rees B, Travis F, Shapiro D, Chant R. Significant reductions in posttraumatic stress symptoms in Congolese refugees within 10 days of Transcendental Meditation practice. J Trauma Stress. 2014;27:112-5. CrossRef

17. Omidi A, Mohammadi A, Zargar F, Akbari H. Efficacy of mindfulness-based stress reduction on mood states of veterans with post-traumatic stress disorder. Arch Trauma Res. 2013;1:151-4. CrossRef

18. Garland SN, Carlson LE, Stephans AJ, Antle MC, Samuels C, Campbell TS. Mindfulness-based stress reduction compared with cognitive behavioral therapy for the treatment of insomnia comorbid with cancer: a randomized, partially blinded, noninferiority trial. J Clin Oncol. 2014; 32:449-57. CrossRef

19. Hubbling A, Reilly-Spong M, Kreitzer MJ, Gross CR. How mindfulness changed my sleep: focus groups with chronic insomnia patients. BMC Complement Altern Med. 2014; 14:50. CrossRef

20. Ong JC, Shapiro SL, Manber R. Mindfulness meditation and cognitive behavioral therapy for insomnia: a naturalistic 12-month follow-up. Explore (NY). 2009;5:30-6. CrossRef

21. Britton WB, Bootzin RR, Cousins JC, Hasler BP, Peck T, Shapiro SL. The contribution of mindfulness practice to a multicomponent behavioral sleep intervention following substance abuse treatment in adolescents: a treatmentdevelopment study. Subst Abus. 2010;31:86-97. CrossRef

22. Jain S, Shapiro SL, Swanick S, et al. A randomized controlled trial of mindfulness meditation versus relaxation training: effects on distress, positive states of mind, rumination, and distraction. Ann Behav Med. 2007;33:11-21. CrossRef

23. Shapiro SL, Oman D, Thoresan CE, Plante TG, Flinders T. Cultivating mindfulness: effects on well-being. J Clin Psychol. 2008;64:840-62. CrossRef

24. Krusche A, Cyhlarova E, Williams JM. Mindfulness online: an evaluation of the feasibility of a web-based mindfulness course for stress, anxiety and depression. BMJ Open. 2013;3:e003498. CrossRef

25. Bazzan AJ, Zabrecky G, Monti DA, Newberg AB. Current evidence regarding the management of mood and anxiety disorders using complementary and alternative medicine. Expert Rev Neurother. 2014;14:411-23. CrossRef

26. Fjorback LO, Arendt M, Ornbøl E, Fink P, Walach H. Mindfulness-based stress reduction and mindfulnessbased cognitive therapy: a systematic review of randomized controlled trials. Acta Psychiatr Scand. 2011; 124:102-19. $\underline{\text { CrossRef }}$
27. Goyal M, Singh S, Sibinga EMS. Meditation programs for psychological stress and well-being: a systematic review and meta-analysis. JAMA Intern Med. 2014; 174:357-68. CrossRef

28. Krisanaprakornkit T, Sriraj W, Piyavhatkul N, Laopaiboon M. Meditation therapy for anxiety disorders. Cochrane Database Syst Rev. 2006;(1):CD004998. CrossRef

29. Ospina MB, Bond K, Karkhaneh M, et al. Meditation practices for health: state of the research. Evid Rep Technol Assess (Full Rep). 2007;(155):1-263.

30. Canter PH, Ernst E. The cumulative effects of Transcendental Meditation on cognitive function--a systematic review of randomised controlled trials. Wien Klin Wochenschr. 2003;115:758-66. CrossRef

31. Hughes JW, Fresco DM, Myerscough R, van Dulmen MH, Carlson LE, Josephson R. Randomized controlled trial of mindfulness-based stress reduction for prehypertension. Psychosom Med. 2013;75:721-8. CrossRef

32. Canter PH, Ernst E. Insufficient evidence to conclude whether or not Transcendental Meditation decreases blood pressure: results of a systematic review of randomized clinical trials. J Hypertens. 2004;22:2049-54. CrossRef

33. Lauche R, Cramer H, Dobos G, Langhorst J, Schmidt S. A systematic review and meta-analysis of mindfulness-based stress reduction for the fibromyalgia syndrome. J Psychosom Res. 2013;75:500-10. CrossRef

34. Jedel S, Hoffman A, Merriman P, et al. A randomized controlled trial of mindfulness-based stress reduction to prevent flare-up in patients with inactive ulcerative colitis. Digestion. 2014;89:142-55.

35. Nash JD, Newberg A. Toward a unifying taxonomy and definition for meditation. Front Psychol. 2013; 4:806. CrossRef

36. Caspi O, Burleson KO. Methodological challenges in meditation research. Adv Mind Body Med. 2007;22:36-43.

37. Valley Mindfulness. Programs and services. http://www. valleymindfulness.com/programs.html. Accessed October 23, 2014.

38. Stress Resources LLC. Mindfulness based stress reduction (MBSR). http://stressresources.com/mbsr.html. Accessed October 23, 2014.

39. MBSR Ottawa. Program costs. http://mbsrottawa.com/. Accessed October 23, 2014.

(C) 2015 Aurora Health Care, Inc. 